\title{
The Exploration of Practice Teaching Quality Monitoring System Construction in Private Application-oriented Colleges and Universities
}

\author{
Hao Liu, Jianxin Xie, Fengyun Yuan, Dongling Cai \\ Qingdao Huanghai University, Qingdao, China
}

Keywords: private application-oriented universities; practice teaching system; quality monitoring

\begin{abstract}
The teaching quality is the lifeline of survival and development of colleges and universities. Constructing practice teaching quality monitoring system adapting to the development of colleges and universities for private application-oriented universities, is an important approach to guarantee and improve the quality of teaching. Through the analysis of the current situation of practice teaching quality monitoring in private universities, it is necessary to adopt countermeasures from the five aspects, including improving the quality management system, clearly monitoring the subject of implementation, reforming the implementation mode of practice teaching process, innovating the learning process monitoring to students and constructing practical teaching mode of social needs, so as to improve practical teaching facilities through school-enterprise cooperation and school resource sharing, and establish multi-channel practical teaching quality monitoring system.
\end{abstract}

\section{Introduction}

Education teaching quality is the foundation of private application-oriented undergraduate colleges and universities, and practical teaching is an important link in cultivating application-oriented talents. At present, the quality control of teaching in private university is mainly focused on the quality control of theoretical teaching. And the quality monitoring of practical teaching in most universities is weak in the most private universities. Evaluation usually adopts methods such as student evaluation, corporate feedback, and teacher evaluation. It only pays attention to the results and can not effectively reflect the quality of practical teaching. Therefore, the research on the quality monitoring of the practical teaching system of private application-oriented undergraduate university is conducive to the cultivation of application-oriented talents suitable for social needs and the sustainable and healthy development of private colleges and universities.

\section{Problems in Practical Teaching Monitoring System in Private Application-oriented Colleges and Universities}

The talent training program is the main basis of teaching quality control, and the practical teaching target system is formulated according to the professional talent training program. When revising personnel training programs, colleges and universities generally issue guidance on the revision of professional personnel training programs. It is required to adapt to the demand for talents of the new normal of local economy. Application-oriented universities emphasize that the training target should meet the requirements of application-oriented talents training, and the practical teaching should be oriented by the position ability of enterprises. In the process of implementation, although every major visit enterprises and demonstrate personnel training program links according to the requirements. Due to the depth and quantity limitation of visiting enterprises, as well as the differences in the requirements of the post capacity of enterprises, the goal system of establishing the practical teaching system is often one-sided. As the maker of the target system of practical teaching, teachers are not accurate in understanding social needs, resulting in too much deviation, between students' practical ability and training social needs.

As for private undergraduate universities and colleges, there are some defects in the establishment of management institutions due to the lack of teaching experience and the limitation of teaching cost. All colleges and universities have educational supervision and inspection 
institutions, but they focus on theoretical teaching, even if there is practical teaching content, it is relatively simple. The relevant regulations and evaluation mechanism of the practical teaching system are deficient, even lacking. Some universities have set up practice teaching section, and daily work generally focus on the skills contest, the graduation design, the information statistics, etc, but for monitoring of the practice teaching quality, especially controlling of the process quality is not strong enough. Part of comprehensive practice curriculum training or practice instruction content is old, not update in time. Due to the lack of teachers' experience in private undergraduate colleges and universities, most of the instructions are copied from those of other public universities, So it is difficult to guarantee if it conforms to the requirements of target system. When conducting teaching supervision inspection, when conducting teaching supervision inspection, we often check whether there is any format problem and ignore the content.

Due to the limitation of private colleges and universities' funds, it has certain influence on laboratory construction, experimental consumables, practical training places and so on, so that practical teaching cannot be carried out smoothly. Some laboratory experimental projects cannot be opened $100 \%$, some laboratories can only demonstrate experiments, and even some professional laboratory visits in colleges and universities are more significant than practical applications. In addition, some specialized laboratories are too expensive to build and maintain for private colleges and universities.

Private schools do not pay enough attention to the construction of practical teaching teachers. Most of them do not have a single team of experimental teachers. Teachers often undertake both theoretical and practical teaching tasks. Due to the large teaching task, teachers focus on theoretical teaching, teaching and research, and pay insufficient attention to practical teaching. Teachers in private colleges and universities are generally from school to school and lack practical teaching experience. If the school does not pay attention to the training of teachers' professional skills, the quality of practical teaching is difficult to be guaranteed. In addition to the serious brain drain of private teachers, the talent structure of experienced teachers in practical teaching is increasingly unreasonable.

The quality control of private colleges and universities is mainly focused on the results, and the process monitoring is often neglected. Because of the imperfection of the quality control system of practical teaching, the cultivation of students' practical ability cannot be guaranteed. For example of graduation practice, the class size of private colleges and universities is generally large, enterprises considering the interests, safety and other issues, generally will not allow students to really study in depth. In addition to the short teaching schedule, the student internship will generally become a visiting internship. The practice teaching quality control system is not complete, and the direct result is that it is difficult to meet the requirements of application type.

\section{Strategy for Practical Teaching Monitoring System in Private Application-oriented Colleges and Universities}

Practice teaching links include in experimental class teaching, military training, school education, professional cognition practice, engineering cognitive practice, concentrated experimental training, curriculum design, graduation practice and graduation design (paper), subject competition, scientific research training, entrepreneurship practice, textual research employs, students participate in style art competition, social practice and volunteer service, social work and community activities. The practical teaching links i trains students' ability of combining theory with practice and solving practical problems, and it is the implementation way of application-oriented talents training. Whether student training meets the requirement of application type, the implementation of practical teaching links plays a key role. Therefore, the effectiveness of the practical teaching quality monitoring system is an effective guarantee of teaching quality.

In order to ensure the quality of practical teaching, it is necessary to establish a practical teaching monitoring management system. The management system of the school level shall be responsible for the top-level design and macro management. The secondary school as the main body of monitoring management; teaching and research section and laboratory as a direct monitoring 
implementers; In this way, a multi-level monitoring and management organization will be formed, and each level will give feedback to each other, forming a clear and effective organization and management organization with clear division of responsibilities, as shown in figure 1.

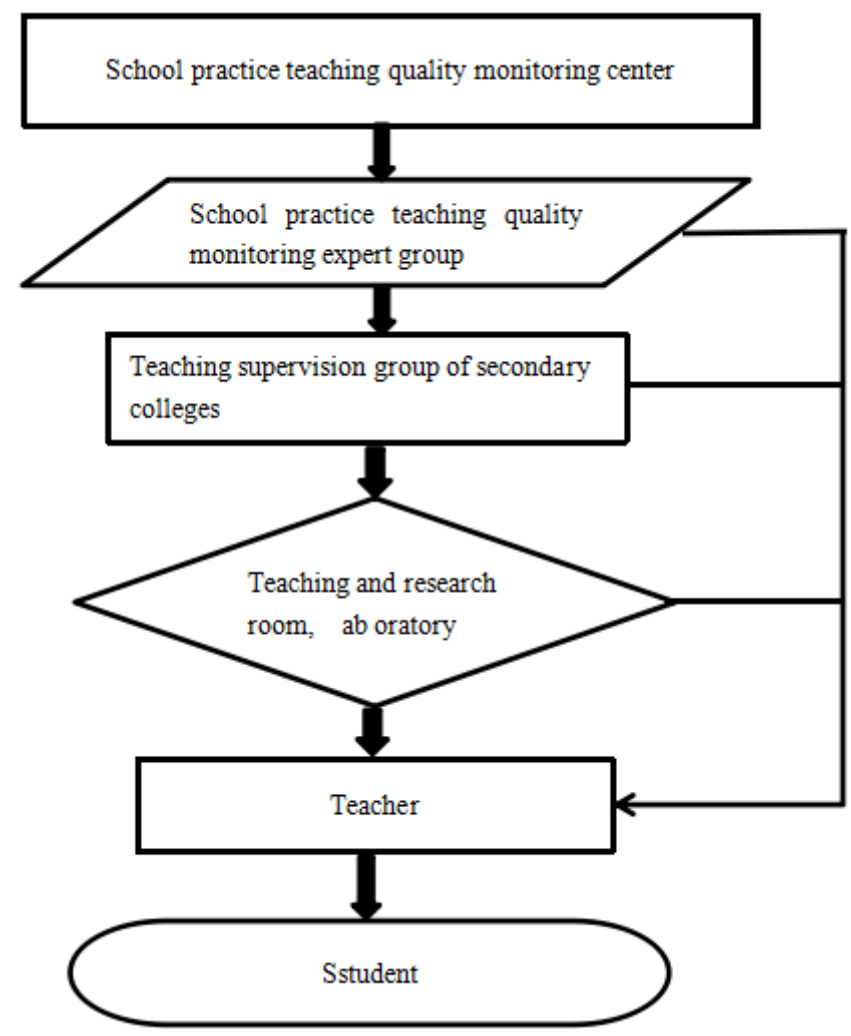

Fig. 1 Organizational management of quality control and evaluation of practical teaching

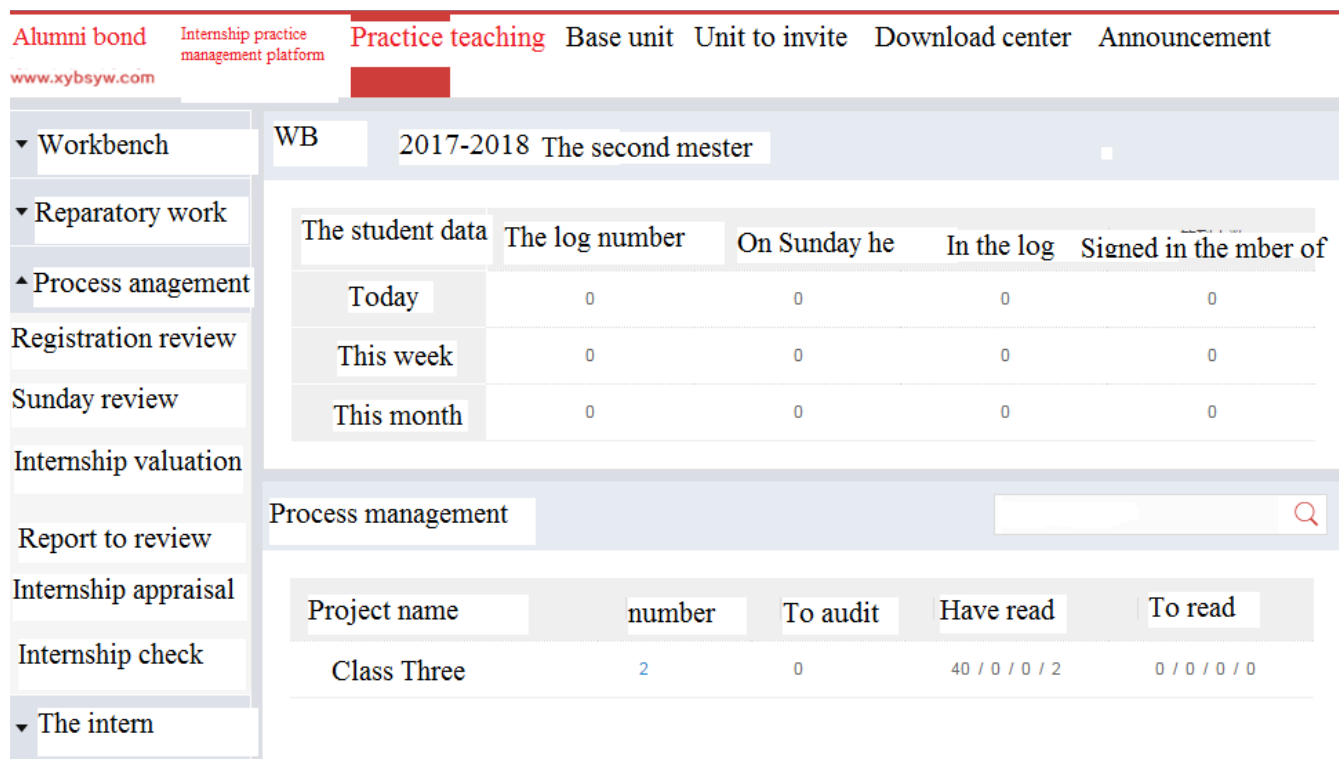

Fig. 2 Practice management platform of alumni states

During the implementation of practical courses, students often cut corners on work, and plagiarize, it should change the process monitoring according to the characteristics of practical courses. For example, in graduation practice, it is difficult to monitor the process of students' independent internship in graduation practice in the past. The final paper version of the internship log submitted by the students makes it difficult for the instructor to distinguish the authenticity. The network management system can be used to monitor the real-time process of students. For example, many colleges use the alumni state internship management system. As shown in figure 2, the effect is obvious. The student apply for it in the system firstly; Then the internship units and jobs 
position was , examined and approved by instructor; Students must submit an internship log every day, The instructor conducts the review and inspection; Finally, students submit the internship report. The tutor and the company give the internship results and evaluation respectively. Instructor can know students' work every day. Compared with the previous paper version of the internship log, the instructor can only review the internship log at the end of the internship. It is greatly improved the efficiency of process management.

How to build a practical teaching model to meet the needs of society in order to cultivate high quality application-oriented professionals is an important problem to be solved in professional construction. For an example of a university of ship and ocean engineering major, is facing that students know little about ship manufacturing process; shipyard's practice is difficult; the practice teaching modules are independent of each other shortcomings.

By conducting school investigation, visiting with industry enterprise, combining with the characteristics of the "work-integrated learning, produced between colleges", mading a further exploration especially on the "three joint", build the "One body, two wings, three docking" practice teaching mode, as shown in figure 3. "One body": taking ship design and construction process as the main line; "Two wings": namely, the combination of the real and the imaginary, the ship manufacturing simulation is virtual, and the hull section model project is real; "Three docking": connecting the professional chain with the industrial chain, the course content with the vocational standard, and the teaching process with the production process.

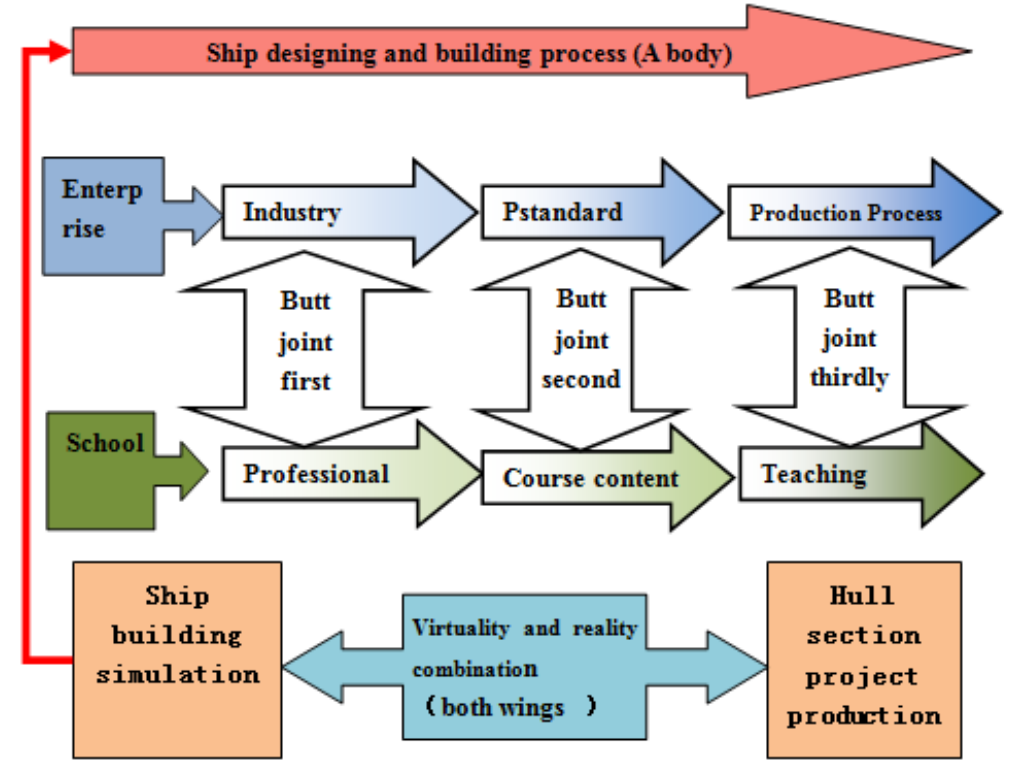

Fig. 3 Practical teaching mode of "one body, two wings and three docking"

Enhancing university-enterprise cooperation research and development, "do major using professional advantage, do a good job in industry to promote professional" new ideas, combining professional construction and industrial development, help to walk the road of healthy development of the college. In practice teaching, construction of practice bases, teachers training, technical exchanges, the respect such as student employment in-depth cooperation, to "go out and walk into, please come in" become the new normal university-enterprise cooperation. Using enterprise resources to build the laboratory together will not only save the cost of laboratory construction, but also bring the profession closer to the needs of enterprises. The purpose of improving practical teaching facilities is to make use of the practical resources of public university laboratories around the university and share them. School-enterprise cooperation and school-school resource sharing can not only solve the shortage of funds for the construction of private colleges, but also strengthen the communication with enterprises and universities, which is more conducive to professional development.

Firstly, we will improve the teaching supervision mechanism at both levels of the school and the 
college, and clarify the supervision tasks of the practical teaching system. Improving the teaching supervision mechanism at the two levels of school and college; grasping the key to improve the quality of practical teaching; Unimpeded information channel, giving full play to the role of supervision. Secondly, Strengthen the routine examination of teaching. According to the regular teaching inspection at the beginning, middle and end of the period, special examination items of practical teaching links are set up. Thirdly, Establishing a system for the teaching feedback reporters, collecting and feedbacking the information of teaching and teaching management extensively and timely; strengthening the connection and communication among the students, teachers, and teaching management staffs; Timely understand and correct problems and deficiencies in teaching and teaching management; Promoting the construction of teaching and learning styles to ensure the quality of practical teaching. Fourth, Organizing student symposiums regularly to understand the students' practical teaching and learning dynamics, and timely grasp the teaching status. Fifth, through the student appraisal teaching, the peer appraisal, and the leadership appraisal mechanism, the quantitatively assess the practice teaching dynamics. Sixth, establishing a reasonable listening system. Through demonstration classes, observation classes and other forms, strengthen teachers'practical teaching exchanges, and improve the teaching level. Seventh, Establish information feedback, improve the system and set up special personnel to collect feedback information, and puts forward reasonable improvement measures, forming a good and effective operation of evaluation - feedback - improvement - improvement - improvement - re-evaluation. As shown in figure 4.Carry out the system of "three checks, three meetings and three comments" in daily teaching. Through the channels of supervision, listening, feedback and investigation of student information personnel, problems in teaching work are timely discovered and the teaching quality is monitored regularly.

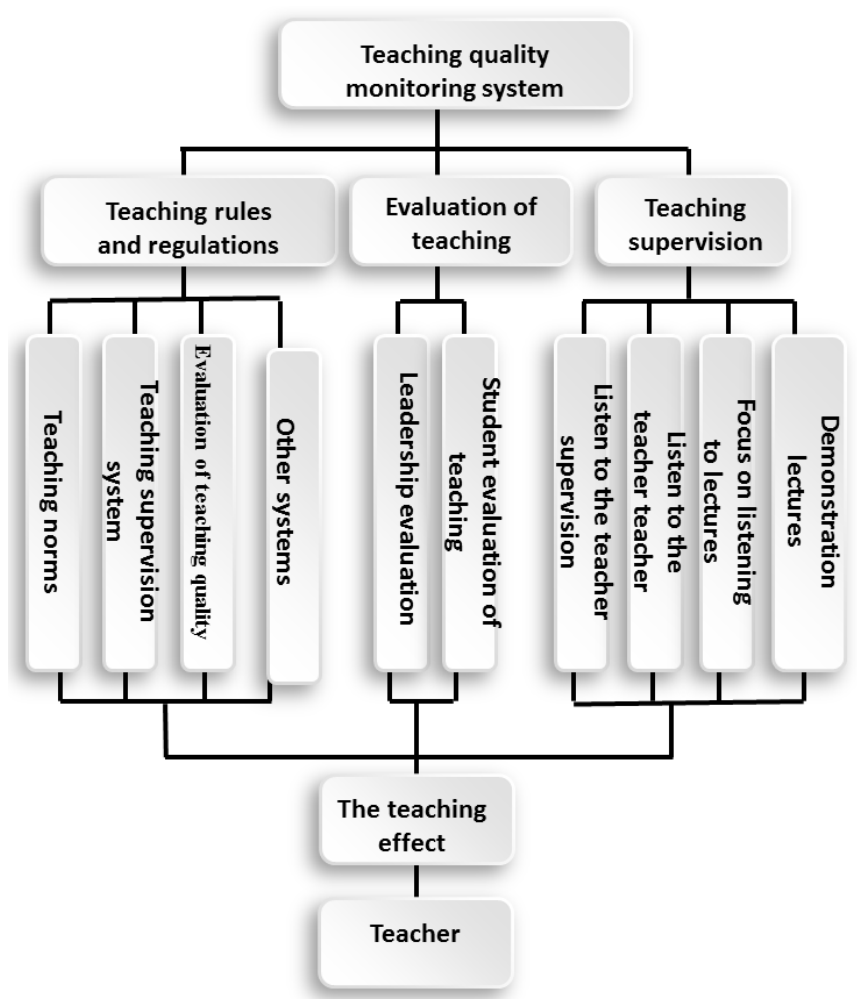

Fig. 4 Multi-channel practice teaching quality monitoring system

\section{Conclusion}

All in all, according to the flexible running mechanism of private undergraduate universities and colleges, actively explore a new approach of practice teaching quality monitoring. Under the guidance of the CPC central committee and the state council on comprehensively deepening the reform of the construction of teachers in the new era, explore the practical teaching quality 
monitoring system of the school, and set up a set of practical teaching quality monitoring and evaluation system which is suitable for the school situation, guaranteeing teaching quality, self-monitoring and virtuous circle. Improve the overall quality of teaching, and cultivate more application-oriented graduates with social needs. Make that private applied undergraduate colleges and universities serve the local characteristic industries better and more obvious effect.

\section{Acknowledgment}

Funded project of Qingdao Huanghai College: Strategy exploration of practice teaching quality monitoring and evaluation system in private universities (2016jiaoxue03).

\section{References}

[1] Chen Baoqi, Reflections on Constructing the Supervision System of Practical Teaching Quality in Colleges and University [J], Education Teaching Forum, 2017(40):234-235.

[2] Wang xiaowu. Practice and Exploration of Developing Internal Teaching Quality Monitoring Mechanism of "Three Levels, Four Supervisions and Five systems" in Private Undergraduate Colleges and Universities-A Case Study of Anhui Xinhua University[J], Journal of West Anhui University, 2016,32(03):45-49.

[3] Li Juan, Lu Xin, Zhou Ke, LIANG Tao, Research on Practical Teaching Quality Monitoring System of Application - oriented Universities[J], Journal of Hubei Correspondence University, 2017,30(24):18-19+51.

[4] Yan hui, Yu Xianxian, Local Undergraduate Colleges and Universities of the Construction of Practical Teaching Quality Monitoring System[J], Education Teaching Forum, 2017(10):83-84.

[5] Hu Xue, Rational Construction of Teaching Quality Monitoring and Evaluation System in Private Colleges [J]. Education Modernization, 2017, 4(49):188-189+212.

[6] Dai Yue, Gu Liying, Discussion on the Quality Monitoring System of Practical Teaching of Local Universities Journal of Guiyang University(Social Sciences), 2018,13(02):104-108.

[7] Xian Xuefeng, Li Jinxiang, Zeng Hai, Research and Practice on Teaching Quality Monitoring and Evaluation System in "Internet Plus” Era [J], Journal of Suzhou Vocational University, 2018, 29(01):43-47. 